Derleme / Review Paper

\title{
Nefelinli Siyenit: Bir Gözden Geçirme
}

\author{
Nepheline Syenite: A Review \\ Serhan HANER ${ }^{1} \mathbb{D}$, Murat DEMI'R ${ }^{2} \mathbb{D}$ \\ ${ }^{1}$ Süleyman Demirel Üniversitesi, Güzel Sanatlar Fakültesi, ISPARTA \\ ${ }^{2} B \& S$ Yatırım A.Ş., Kırşehir Nefelin İşletmeleri, KIRŞEHIR
}

\section{ÖZ}

Nefelinli siyenit, nefelin, sodyum ve alkali feldispatlardan oluşmuş silisçe fakir siyenitik bir kayaçtır. Yerkürede geniş bir yayılıma sahip olmasına rağmen ekonomik değere sahip yatak oluşumları sınırlıdır. Ticari anlamda nefelinli siyenitin en az \%20 nefelin ve \%60 feldispat içermesi gerekmektedir. Bu tip ekonomik sayılabilecek yataklar Rusya, Kanada, Norveç, Brezilya, Çin ve Türkiye'de bulunmaktadır. Nefelinli siyenitin ana kullanım alanlarını cam ve seramik sanayileri oluşturmaktadır. Sağlık gereçleri, porselen, karo, cam, fiberglas gibi ürünlerde ergitici olarak rol oynayan bir alümina $\left(\mathrm{Al}_{2} \mathrm{O}_{3}\right)$ kaynağıdır. Seramik ve cam ürünlere kattığı çok sayıdaki avantaj sayesinde Asya, Avrupa ve Amerika kıtalarında tüketimi yüksek seviyelerde olmaktadır. Bu derleme çalışmasında nefelinli siyenitin özellikleri, oluşumu, üretimi ve tüketimi, kullanım alanları, teknolojisi hakkında bilgiler verilmişsir.

Anahtar Kelimeler: Feldispat, Magmatik kayaç, Nefelin, Nefelinli siyenit.

\begin{abstract}
Nepheline syenite is a siliciously poor syenitic rock composed of nepheline, sodium and alcaline feldspars. Although it is wide spread on the earth, the nepheline deposits that have economic value are limited. Commercially speaking, nepheline syenite contains at least 20\% nepheline and $60 \%$ feldspar. Such economic deposits are in Russia, Canada, Norway, Brazil, China and Turkey. Main uses of nepheline syenite are glass and ceramic industries. It is a source of alumina $\left(\mathrm{Al}_{2} \mathrm{O}_{3}\right)$ and plays a role of melting products such as sanitary ware, porcelain, tile, glass and fiberglass. Because of the numerous advantages on ceramic and glass products, its consumption is high in Asia, Europe and America. In this review, characteristics of nepheline syenite, its formation, production and consumption, usage areas and technology are given.
\end{abstract}

Keywords: Feldspar, Igneous rock, Nepheline, Nepheline syenite. 
Haner, Demir

\section{GíRiş}

Nefelinli siyenit, büyük ölçüde nefelin, sodyum feldispat (albit) ve alkali feldispattan (ortoklas, mikroklin) oluşmuş açık renkli, iri kristalli, silisçe fakir, feldispatik, plütonik magmatik bir kayaçtır. Nefelinli siyenit, temelde siyenittir. Sodalit, öjit, ejirin, biyotit, hornblend, sfen, zirkon, demir oksit (manyetit), apatit, granat, muskovit, korundum ve diğer alkaliler ya da nadir toprak elementlerince zengin iz mineraller içerir. Alterasyon sonucunda sodalit, kankrinit, zeolit türleri ve özellikle de analsime dönüşür. Dünyada geniş yayılımlıdır. Ancak ticari olarak Rusya, Kanada, Norveç, Brezilya, Amerika Birleşik Devletleri, Çin ve Türkiye'de işletilmektedir.

Nefelinli siyenit, cam, seramik ve boya imalatında başlangıç malzemesi olarak kullanılmaktadır. Serbest silis içermemesi, yüksek alkali ve alümina içeriği, yüksek ergitme gücü ve dar erime aralığı, cam endüstrisine ideal uyum gösteren özellikleridir. Ayrıca, yüksek direnç ve hava koşullarına karşı sağladığ1 dayanım özellikleri sayesinde çatı parçacıkları, yol malzemeleri, taş kaplamalarının yanı sira beton agregası ve asfalt üretiminde de kullanımına olanak sağlamaktadır. Nefelinli siyenit, pigment ve dolgu maddesi temel reçetesinde arzu edilen yüksek parlaklık, inertlik ve düşük 1slatma ve yayılım sağlamaktadır. Morötesi azaltma karakteristikleri açık hava şartlarına karşı direnç gösterdiğinden, asfalt çatıların bozulmasını önleyen ve güneş ışılnlarını bloke eden çatı parçacıkları olarak kullanılmasına neden olmuştur. İnce tane boyutunda olanı, tuğla ve sıkıştırma dolgusu imalatında eritken ve renk verici olarak kullanılmaktadır. Boyutlandırılmış ve kırılmış kayaç olarak yerel ihtiyaçlar için de kullanılmaktadır. Kuvars ya da serbest silis içermemesi ve göreceli sertliği nedeniyle silis içermeyen aşındırıcı olarak kullanımına imkan vermektedir. Diğer potansiyel kullanım alanları ise suni gübre, refrakter, çimento harcı ve kağıttır (McLemore vd., 2006).

Nefelinli siyenit, Türkiye açısından da potansiyel feldspat kaynağ 1 olarak gelecekte birçok kullanım alanı bulacaktır. Kırşehir Masifindeki sodalitli siyenit ve miyaskit türü kayaçlar, zenginleştirme çalışmaları sonucunda Norveç nefelinli siyenitine eşdeğer alkali zenginleșmesi ve demir oksit/karbonat safsızlıkları alt limit değerlerinde oldukça iyi verimle kazanılmıştır (McLemore vd., 2006; MTA, 2016).

$\mathrm{Bu}$ çalışmada, nefelinli siyenitin oluşumu, özellikleri ve bazı ekonomik faktörleri hakkında bilgiler verilmiştir.

\section{JEOLOJI}

\section{Nefelinli Siyenitin Mineralojisi, Fiziksel ve Kimyasal Özellikleri}

Kayacın endüstriyel özelliklerini temin eden nefelin minerali, $\mathrm{Na}_{3} \mathrm{KAl}_{4} \mathrm{Si}_{4} \mathrm{O}_{16}$ kimyasal bileşimine sahip, $\mathrm{Na} / \mathrm{K}=3 / 1$ olan, hekzagonal sistemde kristallenen, Mohs sertliği 5-6 ve özgül ağırlığı 2.5-2.7 $\mathrm{g} / \mathrm{cm}^{3}$ olan bir mineraldir. Kimyasal adı sodyum ve potasyum alüminosilikattır. Siyenitin içindeki az miktardaki kuvarsın ve/veya bir miktar feldspatın yerini nefelin alırsa ortaya nefelinli siyenit çıkmış olur. Tipik bir nefelinli siyenitte, yaklaş1k olarak $\% 25$ nefelin, $\% 20$ mikroklin ve $\% 55$ albit vardır (Ciullo, 1996).

Siyenit, alkalilerce zengin (\% 65-90) magmanın derin ortamlarda yavaş soğuması nedeniyle, iri kristalli derinlik kayacıdır. Kristaller, çoğunlukla alkali feldispattan ve az miktarda ortoklaz, albit, pertit ve mikroklinden 
oluşmaktadır. Siyenitin düşük oranlardaki diğer bileşenleri kuvars, ferromanganezler (biyotit, hornblend, piroksen) ile apatit, zirkon, titan, manyetit, melanit ve pirit gibi aksesuar minerallerdir. Nefelin ise siyeniti büyük yüzde ile oluşturan sodyumlu alüminyum silikat olup, feldispatoid grubu bir mineraldir. Nefelinli siyenitin bazı türleri: kongressit, kregmantit, ditroit, fenit, foyait, iyolit, laurdalit, litfieldit, melteigit, miyaskit, monmoutit, raglanit, rouillit ve urtit'tir (Tait vd., 2003; O’Connor, 2011).

Nefelin, nefelinli siyenitin, nefelin monzonitin ve nefelinitin büyük oranda bileşenidir. $\mathrm{Bu}$ kayaçların birbirilerine göre farkı, içerdikleri feldispat türü ve miktarlarıdır. Nefelinli siyenitte feldispat en önemli bileşendir. Nefelin monzonitte K-feldispat ve plajioklas eşit oranlarda bulunur. Nefelinitte ise daha az feldispat ve büyük oranda nefelin vardır (McLemore vd., 2006).

Nefelinin, nefelinli siyenit ile karıştırılmaması gerekir. Dolayısıyla kimyasal ve fiziksel özellikleri tamamen farklıdır. Saf nefelinin erime noktası oldukça yüksek ve $1520^{\circ} \mathrm{C}$; Na-feldispatın $1118^{\circ} \mathrm{C}$; K-feldispatın $1150^{\circ} \mathrm{C}$ ve nefelinli siyenitin $1223^{\circ} \mathrm{C}^{\prime}$ dir. Diğer feldispatlarla karşılaştırıldığında, $\mathrm{Na}$ ve $\mathrm{K}$ oranı oldukça yüksektir. $\mathrm{Na}_{2} \mathrm{O}+\mathrm{K}_{2} \mathrm{O}$ oranı yaklaşı olarak \%9-15 arasındadır. Nefelinli siyenit, ürünlerin kompozisyonuna alümina $(>\% 23)$ ve alkali kaynağı olarak katılmaktadır. Düşük silisten $(<\% 60)$ dolayı serbest kuvars yoktur. Dolayısıyla düşük viskozite ve kolay çalışılabilirliğe olanak sağlamaktadır. Nefelinli siyenit yüksek alümina/ alkali oranına sahiptir (sodyum feldispatta \%30 ve potasyum feldispatta \%32'ye nazaran \%37). $\mathrm{Bu}$ ise aynı erime davranışı elde etmek için daha az malzeme kullanımı anlamına gelmektedir. Alüminanın yüksek olması çizilme dayanımını ve mukavemetini arttırmaktadır. Aynı zamanda 1s1l dayanım ve kimyasal dayanımını beraberinde getirmektedir. Nefelinli siyenit, feldispat gibi cam ya da seramik karışımların ergime sıcaklığını azaltılmasında ergitici olarak davranmaktadır.

Nefelinli siyenit içindeki alkali feldispatta önemsiz bir miktar demir gözlenir. Tipik olarak $\%<0.2 \mathrm{Fe}$ içermektedirler. İçerdiği minerallere göre renksiz, beyaz, gri, krem, yeşil ve kahverengi renklerinde olabilir. Düşük demir içeriği, saydam cam ve fiberglas, pigment ve dolgu gibi diğer nihai kullanımlar için kullanılan toz malzemelerde gerekli beyazlığı sağlamaktadır (McLemore vd., 2006).

Nefelinli siyenit, reaksiyona girmeyen, kimyasal olarak inert ve yanıcı olmayan bir kayaçtır. Tozuna yüksek derecede maruz kalındığında nefes darlığı, akciğer fonksiyonunda azalma belirtileri ile akciğer rahatsızlığ ve silikozise sebep olabilmektedir (MSDS, 2015). 1997'de Grup 2A olas1 kanserojen madde olarak, 1999'da ise Grup 1 kanserojen olarak sınıflandırılmıştır. Kristalin silis, feldispat üreticileri için ciddi bir hastalı nedeni olmaktadır.

Nefelinli siyenit işletmelerinde atık miktarı az olmaktadır ve bu atıklar toksik değildir. Bölgesel olarak toz sorunu oluşmaktadır ve kolaylıkla kontrol altına alınabilmektedir.

\section{Oluşumu}

Siyenitler, baskın felsik mineral olarak alkali feldispat içeren magmatik sokulum kayaçları olarak tanımlanmıştır. Nefelinli siyenitler, silikaya doymamış magmadan oluşmuş siyenitlerdir. Diğer bir deyişle, magmatik kökenli alkalin volkanik kayaçlardır. Nefelinli siyenitler magmatik ayrışmanın çok ilerlemiş döneminde kristalleşirler. Volkanik eşdeğeri fonolittir. Kanada yataklarının bazıları çeşitli bölgesel 
tektonik olaylar esnasında metamorfizma geçirmiştir. Diğer taraftan, daha eski bir yatak olan Finlandiya'daki Livaara yatağı için metasomatik köken önerilmiştir (Tuzcu, 1992; McLemore vd., 2006; O’Connor, 2011).

Nefelinli siyenit tipik olarak sınırları belli rift ilişkili kıtasal kaynak alanlarda nispeten sığ kompleksler bileşeni olarak oluşur. Bazı okyanus sorguç kökenli nefelinli siyenitler Atlantik, Hindistan ve Pasifik okyanusunda bulunmaktadır. Çoğu feldispatımsı kayaçlar gibi nefelinli siyenitler de, doymamış plütonik ve volkanik kayaçlar ile ilişkilidir (Woolley, 1987; Guillet, 1994; Platt, 1996).

Karbonatitler, kimberlitler ve alkali gabrolar ile ilişkili ayrışmış alkali halka komplekslerinde bulunurlar. Bazı bölgelerde agpaitik katmanlanmış (peralkalin) siyenit intrüzyonları yaygındır. Nefelinli siyenit, siyenitler ya da granitlerle ilişkili istifin sınırlarında şekillenebilir. Kanada'da genellikle nefelin pegmatitlerle ilişkili nefelinli siyenit gnaysları yaygındır. Nefelinli siyenit içeren alkali kompleksler genel olarak küçük ve düzensizdir (McLemore vd., 2006).

\section{DÜNYA NEFELINLI SIYYENIT REZERVLERİ VE FAALIYETLERİ}

Tipik olarak alkali ya da karbonatit kompleksler ile ilişkili nefelinli siyenitler dünya genelinde ekonomik ve akademik alanlarda büyük ilgi görmektedir. Apatit (fosfat minerali), nadir toprak elementleri (NTE), niyobyumtantal, uranyum-toryum, korundum ve diğer ekonomik tipteki yataklar ile bulunabilirler. Cam ve seramikte kullanılabilecek ekonomik nefelinli siyenit yataklarına ender rastlanır. Çünkü genellikle düşük miktarda demir içeriğine sahip değildirler. Tipik olarak nefelinli siyenit yatakları, farklı hammaddelere ait ekonomik yatakların civarında bulunmazlar. Günümüzde, potansiyel olarak cam ve seramikte kullanım için uygun olan bazı nefelinli siyenit yatakları ekonomik olarak görülmemektedir. Çünkü bu yataklar, potansiyel pazarlardan çok uzaktır ya da mevcut ulaşım olanakları yetersizdir. En büyük rezervler ve küresel nefelinli siyenit üreticileri Rusya, Kanada, Amerika Birleşik Devletleri, Norveç, Brezilya, Çin ve Türkiye'de bulunmaktadır (Şekil 1, Çizelge 1). 2013 yılında dünya genelinde, 59.3 milyon dolar tutarında (491.000 ton) nefelinli siyenit ithalatı yapılmıştır (McLemore vd., 2006; Tanner, 2015). 


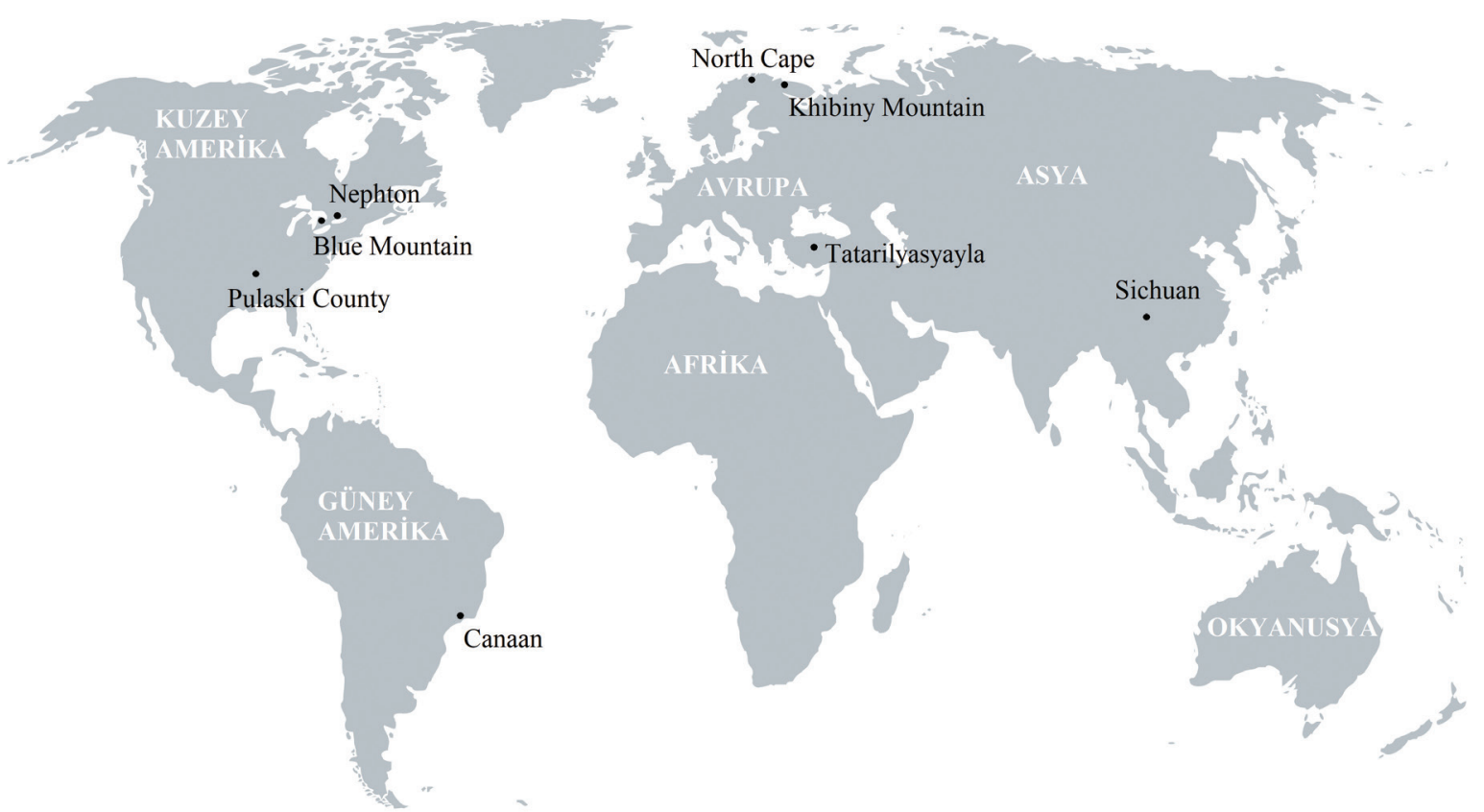

Şekil 1. Başlıca nefelinli siyenit üretilen yatakların konumu.

Figure 1. Location of major nepheline syenite deposits.

Çizelge 1. Başlıca nefelinli siyenit madenleri ve yatakları (McLemore vd., 2006; Brown vd., 2017).

Table 1. Major nepheline syenite mines and deposits (McLemore et al., 2006; Brown et al., 2017).

\begin{tabular}{|c|c|c|c|c|}
\hline Yatak, Yer & Şirket & $\begin{array}{l}\text { Madencilik } \\
\text { Metodu }\end{array}$ & $\begin{array}{l}\text { Başlama } \\
\text { Tarihi }\end{array}$ & $\begin{array}{l}\text { Üretim, ton/ } \\
\text { y1l }\end{array}$ \\
\hline $\begin{array}{l}\text { Khibiny Mountain, Kola } \\
\text { Peninsula, Rusya }\end{array}$ & Apatit Production Association & $\begin{array}{l}3 \text { açık ocak, } 2 \\
\text { yeraltı ocağı }\end{array}$ & 1929 & 4.111 .000 \\
\hline $\begin{array}{l}\text { Nephton ve Blue Mountain, } \\
\text { Havelock, Ontario, Kanada }\end{array}$ & Unimin Canada Ltd. & Açık ocak & $\begin{array}{l}1935 \text { ve } \\
1955\end{array}$ & 621.000 \\
\hline $\begin{array}{l}\text { Pulaski County ve Saline County, } \\
\text { Arkansas, ABD }\end{array}$ & $\begin{array}{l}\text { 3M Company ve Granite } \\
\text { Mountain Quarries, Inc. }\end{array}$ & Açık ocak & 1947 & md \\
\hline North Cape, Stjernoya, Norveç & $\begin{array}{l}\text { North Cape Minerals AS } \\
\text { (Unimin mülkiyetinde) }\end{array}$ & Yeraltı ocağ 1 & 1961 & 324.000 \\
\hline Canaan, Rio de Janeiro, Brezilya & Unimin Corporation & $\mathrm{md}$ & 1980 & 134.000 \\
\hline $\begin{array}{l}\text { Sichuan, Shuiye, Anyang, Henan } \\
\text { Province, Çin }\end{array}$ & $\begin{array}{l}\text { Fineton Industrial Minerals } \\
\text { Ltd. }\end{array}$ & Gelişim halinde & 1994 & 50.000 \\
\hline $\begin{array}{l}\text { Buzlukdağ, Tatarilyasyayla, } \\
\text { Kırşehir, Türkiye }\end{array}$ & B\&S Yatırım A.Ş. & Açık ocak & 2008 & 50.000 \\
\hline
\end{tabular}


Haner, Demir

\section{Rusya}

Rusya'daki Apatit Production Association, Khibiny Complex'te bulunan dünyanın en büyük fosfat yatağ1 ve en büyük agpaitik nefelinli siyenit kompleksini işletmektedir (Brown vd., 2017). 1924 y1lında Khibiny Complex'te türüne az rastlanan apatit-nefelin yatakları keşfedilmiştir. $\mathrm{Bu}$ yatak 1929 yılından beri işletilmektedir (McLemore vd., 2006). 1929-2013 y1llar1 arasında Apatit Madencilik tarafindan yaklaşık olarak 67 milyon ton nefelin konsantresi üretilmiştir (Tanner, 2015). Rusya'da sadece 2015 y1lında, 4.111.000 ton nefelinli siyenitin üretimi yapılmıştır.

Apatit-nefelin yatakları ijolit-urtitle ilişkilidir. Agpaitik nefelinli siyenit içerisinde yaklaşık olarak 100 metre kalınlığında ve $11000 \mathrm{~m}$ uzunluğunda yay şeklindedir. Bu yatak \%10-80 nefelin, \%15-75 apatit, \%1-25 ejirin ve \%5-12 sfen, titano-manyetit ve feldispattan oluşmaktadır.

The Apatit Production Association, 11 adet apatit-nefelin maden yatağ 1 keşfetmiştir. $\mathrm{Bu}$ maden yataklarının toplam rezervi 3.6 milyar tondan daha fazladır. $\mathrm{Bu}$ yataklar Yukspor, Kirovsk Saami, Rudnik Rasvumchorr ve Tsentralny'de bulunan üç yeraltı ocağı ve iki açık ocak ile işletilmektedir. İlave olarak, geçmişte Koashva ve Nyorkpakh'ta açılan iki açık ocak ile sfen konsantresinden titanyum-silikon pigment üretimi için deneme çalışmaları yapılmış ve başarılı olmuştur (McLemore vd., 2006).

Nefelinli siyenit, Kola Peninsula'daki Lovozero masifinden üretilen NTE'nin bir yan üründür. $\mathrm{Bu}$ masif, eudialytik siyenit ve foyait, urtit, lujavrit ve ilişkili kayaçların alternatif tabakalarını içeren tabakalı bir topluluktur. Loparit, madenden çıkartılan baskın NTE mineralidir (McLemore vd., 2006).

\section{Kanada}

Kanada'da nefelinli siyenit yatakları 1890'larda keşfedilmiştir. Ancak nefelinli siyenitin üretimine 1935 y1lında Nephton ve 1955 yılında Blue Mountain ile başlanmıştır (Unimin, 2014). Cam ve seramik endüstrileri için batı yarım küredeki en büyük nefelinli siyenit yatakları Ontario'da (Blue Mountain, Havelock ve Nephton) bulunmaktadir. Blue Mountain nefelinli siyenit rezervi 30 milyon tonu aşmaktadır. Mekhuen kasabasındaki Peterborough'un yaklaşık olarak 58 km kuzeydoğusundadır. $\mathrm{Bu}$ yataklara otoyol ve demiryolu ile ulaşım mümkündür. Kuzey Amerika'nın ilk nefelinli siyenit işletmesidir. Unimin Corporation, 1990 yılında Indusmin Division of Falconbridge Ltd.'den yatağ1 satın aldığında dünyadaki büyük nefelinli siyenit ve feldispat üreticilerinden biri haline gelmiştir.

Blue Mountain ve Nephton nefelinli siyenitleri güney Ontario'nun Grenville Province'deki nefelinli siyenit gnayslarının 1280 km'lik kuşağının bir parçasıdır. Blue Mountain nefelinli siyenit gnaysları, yaklaşık olarak 2130 metre uzunluğa 1000 metre genişliğe sahip gözyaşı damlası şeklinde homojen bir kütledir. Yatağ1, epidot-amfibol metasedimanter kayaçlar çevrelemektedir. Tipik olarak nefelinli siyenit, granitik doku ile iriden orta taneli beyaz kayaca katmanlanmıștır. Albit (\%50-54), mikroklin $(\% 20)$, nefelin $(\% 22-30)$, mafik mineraller $(\% 4)$ ve diğer aksesuar mineraller (ejirin-öjit, andradit, biyotit, kalsit, kankrinit, korundum, hastingsit, hornblend, manyetit, muskovit, riebeckit ve zirkon) içermektedir. $\mathrm{Bu}$ yatak, homojenliği, orta-kaba tane boyutu ve düşük demir içeriğinden dolay1 ekonomiktir.

Unimin maden çıkartma ve üretim prosesleri için bir dizi kurumekanik işlemler kullanmaktadır. $\mathrm{Bu}$ işlemler kırma, kurutma, taşıma, eleme, 
ögütme ve sınıflandırma içermektedir (Kennedy, 1990; Unimin, 2014).

Kanada'da 2013 yılında üretilen 674.000 ton nefelinli siyenitin 545.000 tonu ihraç edilmiştir (Tanner, 2015).

\section{Amerika Birleşik Devletleri}

Arkansas'tan çıkartılan nefelinli siyenit, güney ve güneydoğu ABD'deki asfalt kiremit endüstrisi için çatı parçacıkları olarak, porselen ve seramik yer karosu üretiminde ergitici olarak kullanılmaktadır (Tanner, 2016). ABD'de 2015 yılında, feldispat ve nefelinli siyenitin yurtiçi kullanımı, camda \%60, seramik karo, çömlek ve diğer kullanımlarda \%40 şeklinde dağılım göstermiştir. ABD'de nefelinli siyenit üretimi yapan iki şirket vardır. Üretilen nefelinli siyenitler $\% 3$ veya daha fazla demir oksit içermektedir. The 3M Co., Industrial Mineral Products Division şirketi, Arch Street madeninden kiremit endüstrisi için nefelinli siyenit sağlamaktadır. Ayrıca 1930'lardan beri kırma taş tesisi aktif olarak üretim yapmaktadır. Granite Mountain Quarries Co. ise, Granite Mountain Quarry \#1 ve Granite Mountain Quarry \#2 madenlerinden nefelinli siyenit çıkartmaktadır. Pulaski County'de 3 ocak ve Saline County'de 1 ocak bulunmaktadır. Bütün maden ocakları, Little Rock Arkansas'ın güney ve güneydoğusunda bulunmaktadır. Arkansas'ta 2008 yılında, agrega dişındaki uygulamalar için yaklaşık olarak toplam 520.000 ton nefelinli siyenit üretilmiştir (Tanner, 2010; Tanner, 2016; Tanner, 2017).

\section{Norveç}

Nefelinli siyenit üretimi Stjernoya Adası'nda 1961 yılından beri yapılmaktadır. 1961-1972 y1lları arasında 9.3 milyon ton üretimden
17 milyon dolar gelir sağlamıştır. Norveç, 2013 y1lında ise 328.000 ton nefelinli siyenit ihracatı yapmıştır. Çoğunluğu Avrupa ülkelerini içeren ihracatın dağ 1 lımı, \%30 Polonya, \%21 Hollanda, \%17 Almanya, \%11 İngiltere şeklinde olmuştur. Zayıf yapraksı biyotit-hornblendpiroksen nefelinli siyenitlerden oluşan bu yatak, mercek şeklinde ve 300 metreye 1700 metre boyutundadır. Feldispat (\%56), nefelin ve az plajioklas $(\% 34)$, hornblend $(\% 0.3-2.5)$, biyotit (\%2.5-6), ejirin (\%1.3-3.8), kalsit, klinopiroksen, titanit (\%iz-1.2) ve manyetit içermektedir. İlişkili kayaçlar, alkali piroksenit, karbonatit ve fenitler içerir. Bu nefelinli siyenit, düşük demir ve kuvars içeriğinden dolayı cam ve seramik endüstrisinde kullanılmaktadır (Sariiz ve Nuhoğlu 1992; McLemore vd., 2006). Rezervi 400 milyon ton civarındadır.

\section{Brezilya}

Canaan'da, Prekambriyen kuvarsofeldispatik gnaysların ve migmatitlerin sokulum oluşturduğu ve alkali siyenitler tarafindan sarılmış $20 \mathrm{~km}^{2}$ 'lik dairesel litfieldit sahası bulunmaktadır. Litfieldit, $\% 55$ mikroklin ve pertit, $\% 20$ nefelin, $\% 15$ albit, $\% 10$ biyotit ve az miktarda kankrinit, sodalit, korundum, zirkon, pirit, manyetit, aksesuar mineraller içermektedir. Ölçülmüş rezerv 1.6 milyon ton, belirlenmiş rezerv 5.7 milyon ton ve mümkün rezerv 25.4 milyon tondur (McVey, 1988; McLemore vd., 2006).

\section{Çin}

100 milyon tondan fazla homojen malzeme içeren Sichuan nefelinli siyeniti, Fineton Industrial Minerals Ltd. tarafından geliştirilmiştir. Ana olarak cam ve seramik derecesinde nefelinli siyenit üretimi yapılmaktadır. Anyang 
nefelinli siyeniti, düşük demir ve yüksek alümina (>\%21) içeriğine sahiptir. Fineton şirketi, işleme teknikleri ve ekipman için ciddi bir değerlendirme gerçekleştirmiş ve 2002'nin ortalarında deneme üretimini tamamlamıştır. Sonrasinda endüstriyel boyutlarda üretime başlamıştır (O’Driscoll, 2005). 2010 y1lında Anyang, Henan, Province' deki tesislerde 50.000 ton civarında nefelinli siyenit üretimi yapılmıştır (Tanner, 2012).

\section{Türkiye}

B\&S Yatırım A.Ș. Nefelin İşletmeleri, Kırşehir merkeze bağlı Tatarilyasyayla köyü Buzlukdağı mevkiindedir. İşletme KırşehirAnkara yoluna $12 \mathrm{~km}$ mesafededir. Nefelinli siyenitin sahadaki görünür rezerv alanı $2250 \mathrm{~m}$ uzunluğa, $1850 \mathrm{~m}$ genişliğe ve $450 \mathrm{~m}$ derinliğe sahiptir. Bu yataktaki toplam rezervin 1 milyar tonun üzerinde olduğu düşünülmektedir. Karo, vitrifiye, firit, porselen, cam, izolatör, çimento, izolasyon ve eletrot sanayilerine uygun özelliklerde nefelinli siyenit üretimi yapılmaktadır (BS, 2015). Buzlukdağ1 siyenitoyidi genel olarak foyid içeren ve tane boyutu açısından ince, orta ve iri taneli olmak üzere üç ana gruba ayrılabilmektedir. İri kristalen, orta kristalen ve ince kristalen foyid siyenitler sirasiyla pembemsi, pembemsi gri ve gri renktedirler. Buzlukdağı foyid siyeniti petrografik olarak benzer mineralojik bileşime sahiptir, ancak farklı mineral oranlarında farklı renklerde kaya gruplarına ayrılmaktadır. Çoğunlukla nefelin, ortoklaz, oligoklaz, piroksen, biyotit, amfibol ile az oranda granat, kankrinit, sfen ve opak minerallerden meydana gelmektedir (Deniz, 2010).

Afyon iline bağlı Ömerli bölgesinde bulunan nefelinit-lösit, camsı bir hamur içinde bulunan biyotit ve nefelin fenokristalleri içermektedir.
Değirmen bölgesinde bulunan nefelin-lösitbazalt, porfirik dokuludur. Olivin kristalleri tamamen limonitleşmiştir. Biyotit, ojit ve nefelin içermektedir.

Amasya merkeze bağl1 Göyüncek ve Merzifon'a bağlı Suluova ve Gümüşhacıköy çevresinde volkanik seriler içerisinde nefelin yataklanmaları mevcuttur.

Ankara-Kırıkkale-Yahşihan bölgesinde analsitleşmiş nefelin lösitit, porfirik dokuludur ve geniş poligonal bir bölgeye sahiptir.

Manisa merkezine bağlı Gördes-Küpbaşı mevkiinde nefelinli bazalt içeriği mevcuttur. Bol miktarda plajioklas ve ojitle beraber nefelin kristalleri içerir. Yüksek derecede gözeneğe sahiptir (Sarıiz ve Nuhoğlu, 1992).

\section{UYGULAMA ALANLARI}

Nefelinli siyenitin, düşük ergime noktası ve erime kabiliyetinden dolay1 1900'lerin başlarından beri cam ve seramiklerde kullanımıyla ilgili birçok çalışma kapsamında araştırılmıştır. Ana pazarları cam, seramik, dolgu, pigment, boya, kaplama ve çatı parçacıklarıdır.

\section{Cam}

Nefelinli siyenitin düz cam, cam elyafı, buzlu cam, elektriksel cam, borosilikat camı ve cam sofra gereçlerinde kullanılabilmesine rağmen en büyük uygulama alanı cam kaplardır. Düz cam ve tekstil cam elyafı $\% 0-0.5$, cam kaplar $\% 8$, özel camlar $\% 11$, yalıtım cam elyafı $\% 18$ nefelinli siyenit içermektedir. Nefelinli siyenit, cam üretimi için gerekli olan alümina ve alkalinin ucuz bir kaynağıdır. Dolayısıyla hammadde maliyetini azaltmaktadır (McLemore vd., 2006). Cam yapımında genellikle -500 $\mu \mathrm{m}$ tane boyutunda kaba öğütülmüş nefelinli 
siyenit kullanılmakta olup, ortalama $\% 23 \mathrm{Al}_{2} \mathrm{O}_{3}$, $\% 15 \mathrm{Na}_{2} \mathrm{O}+\mathrm{K}_{2} \mathrm{O}$ ve $\% 0.10 \mathrm{Fe}_{2} \mathrm{O}_{3}$ içermektedir (McLemore vd. 2006; BS, 2015). Nefelinli siyenit cam kompozisyonuna sağladığ1 alümina katkısı ile son ürünün mukavemetini geliştirir ve yapıda stabilizatör olarak davranmaktadır. İçerdiği alkaliler sayesinde cam hamurunda ergitici olarak davranmaktadır. $\mathrm{Bu}$ da üretimde kullanılan hammaddelerin maliyeti kadar enerji maliyetinde tasarruf sağlamaktadır. Ayrıca viskoziteyi düşürür ve işlenebilirliği arttırmaktadır. Nefelinli siyenitin kullanılması ile kırılmaya karşı daha fazla dirençli cam ürünler elde edilmektedir (Negm vd., 2000).

\section{Seramikler}

Feldispatik malzemeler yüzlerce yıldır seramik formülasyonunda ana ergitici olarak kullanılmaktadır. Nefelinli siyenit bu yüksek rekabet ortamında önemli bir oyuncudur. Seramik endüstrisinde ergitici olarak feldispat, nefelinli siyenit, feldispatik pegmatitler, kaolinize olmuş granit (cornish stone), aplit, üretilmiş feldispatik ergiticiler kullanılmaktadır. Bütün bu malzemeler $75 \mu \mathrm{m}$ 'den daha ince tane boyutlarına öğütülmektedir. Feldispatik seramik ergiticilerinde kaliteyi belirleyen öncelikli ölçütler, tane boyutu ve tane boyut dağılımının yanı sıra safsızlıkların seviyesi, kalsit gibi $\mathrm{CO}_{2}$ çıkartan maddeler, kankrinit ve sodalit çok düşük seviyelerde olmalıdır. Demir gibi maddeler bünyenin rengini bozmaktadır ve $\% 1$ ya da daha düşük miktarlarda olması gerekmektedir. Camlaşma esnasında zararlı etkilerinden dolayı korundum gibi refrakter tanelerinin varlığ1 minimize olmalıdır (Salem vd., 2009; Kundurac1 vd., 2016).

Nefelinli siyenit, seramik sağlık gereçleri, karolar, elektrik porselenleri, sofra takımları ve sırlarda, düşük pişirme sıcaklığı ve hızlı pişirme programına imkan sağlamaktadır. Nefelinli siyenit yer ve duvar karosunda \%1055 , beyaz seramikler ve kimyasal porselenlerde $\% 15-30$, sağlık gereçlerinde $\% 25-35$ ve elektrik porselenlerinde \%30-50 miktarında kullanılmaktadır. Yer ve duvar karosunda diğer alümina kaynaklarından daha düşük su emme ve rutubet genleşmesi, daha iyi mekanik mukavemet ve düşük 1sısal genleşme sağlamaktadır. Nefelinli siyenit beyazlığından dolayı seramik endüstrisi için önemli bir hammaddedir. Nefelinli siyenit ve silis ile plastik kaolen karıştırıldığında çok beyaz camsı ortalama bir sicaklık porseleni elde etmek mümkündür (Dolan vd., 1991; McLemore vd., 2006).

\section{Diğer Uygulamalar}

Nefelinli siyenit, dolgu, dolgu pigmentleri, boya, kaplama ve çatı parçacıklarında kullanılmaktadır. Nefelinli siyenitin yüksek kuru parlaklığı ve aşınma ile kimyasal bozunmaya karş1 direnç göstermesi sebebiyle plastik, kauçuk ve yapışkanlarda dolgu maddesi olarak kullanılmaktadır. Nefelinli siyenit, UV 1şınları azaltma özelliği ve kötü hava şartlarına karşı direnç göstermesi nedeni ile çatı parçacıklarında kullanılmaktadır. $2 \mu \mathrm{m}$ tane boyutuna kadar ögütülmüş nefelinli siyenit ile pigmentler ve dolgularda reaksiyona girmeyen, kolay 1slatma, iyi dağılabilme, dengeli $\mathrm{pH}$ ve aşınma direnci elde edilmektedir. Kırılma indeksi önemli özelliklerindendir. Nefelinli siyenitin kırılma indeksi 1.53'tür ve yaygın olarak vinil reçinelerde kullanılmaktadır. Plastik malzemelerde mikronize nefelinli siyenitin en büyük uygulama alanı çeşitli PVC plastikler ve epoksiler ile polyesterlerdir. Başta Rusya olmak üzere birkaç ülkede nefelinli siyenitin önemli bir miktarı alümina ve alüminyum metalinin üretiminde kullanılmaktadır. 
Nefelinli siyenit, iyi bir dış görünüşe sahip, parlatılabilir, nispeten kırıksız ve homojen olduğundan kesme taş olarak kullanılabilir. Birçok yerde agrega olarak kırılmış nefelinli siyenit kullanılmaktadır. Kumlama için hafif aşındırıcı olarak, kaynak elektrotlarında kaynak tozu olarak ve kaplama tozlarını bağlama ve ektrüzyonu için de kullanılmaktadır.

Kanada'da yüksek demirli nefelinli siyenit, alümina ile silis kaynağı ve düşük maliyetli ergitici olarak mineral yün üretiminde kullanılmaktadır.

Zımpara taşının imalatında yapıştırıcı madde olarak kullanılmaktadır.

Az miktarlarda kaynak elektrodu üretiminde kullanılmaktadır (Dolan vd., 1991; Sariiz ve Nuhoğlu, 1992; McLemore vd., 2006).

\section{TEKNOLOJI}

Çoğu endüstriyel mineralde olduğu gibi bir nefelinli siyenit yatağının da «yer değeri» kritiktir. Arama jeoloğu, arazi incelemesine ilişkin çalışmalara ek olarak, üretim ve ürünlerin piyasaya taşınma maliyetlerini göz önünde bulundurmalıdır. Bilinen bir nefelinli siyenit yatağının işletilmesini etkileyen tüm faktörlerin karşı1ıklı etkileşimi incelenerek, gelişme garantili olup olmadığ belirlenebilir.

\section{Arazi Teknikleri}

Saha jeoloğunun, iri-orta taneli kayaçtan oluşan bir maden yatağ ${ }_{1}$ araması gerekmektedir. Ürünün satılabilir hale gelmesi için, 30 mesh elekten (ABD standartına göre) geçecek şekilde kırılmalı ve ortadan kaldırılması istenilen safsızlıklar uzaklaştırılmalıdır. Madenciliği etkileyebilecek dokusal, yapısal ve mineralojik değişiklikleri ortaya çıkartmak için, maden yatağı dikkatlice haritalanmalıdır. İlk aşamada uygun yöntemle kayacı temsil edecek numuneler seçilmeli ve mikroskopik, fiziksel, kimyasal ve seramik testleri yapılmalıdır.

İnceleme esnasında, safsızlıkların, feldispat kristalleri boyunca ince bölünmüş halde dağ 11 lılı olduğu ortaya çıkarsa, bu maden yatağı cam ve seramik kullanımı için uygun olmayacaktır. Eğer safsızlıklar kırma işlemi ile kolayca ayrılıyorsa, yatak hakkında daha ayrıntılı bir değerlendirme yapılabilir. Normal olarak, feldispatik malzemelerin açık ocak yöntemleriyle çıkarılması beklenmektedir. Belirli bir ocağın yeterli olup olmadığını belirlerken basamak yüksekliklerine, dar basamağa ve madencilik yönetmeliklerine gereken önemin verilmesi gerekir. Alıcılar, tedarik güvencesi talep ettiği için hammadde rezervlerinin uzun süre operasyonu sürdürecek kadar geniş olması gerekmektedir. Dolayısıyla endüstriyel maden işletmelerinde, yatırılan sermayenin geri dönebilmesi için on veya daha fazla y1l gerekebilir. Genellikle, 20 y1ldan daha az işletme süresi olan cevher rezervlerine sahip bir maden yatağı dikkate alınmamaktadır.

Kimyasal bozunmanın etkili olduğu alanlarda, çalıșılacak temiz numuneler bulunmalıdır. Nefelin kaya yüzeylerinden nispeten daha kolay çözünür, feldispat mineralleri kaoline dönüşür, içindeki demir oksitler ve sülfürler de süzülebilir.

Halka kompleks ve karbonatit tipi sokulumlar gibi kompleks nefelinli siyenit yataklar, cam ve seramikte kullanım için çok az umut vaat etmektedir. Bunlar normal feldispat ve mafik bileşenlerde çok değişkendir ve buna ek olarak, nadir toprak elementleri, halojenürler ve diğer birçok iz elementler içerebilir. Bu durum nedeniyle kayaç için tasarlanan birçok uygulama alanında kullanımı sağlanamamaktadır. 


\section{Sondaj}

Kayaçların yapısını görebilmek ve laboratuvar çalışmaları için sondaj yapılması gerekmektedir. Şartlara bağlı olarak, AX, BX ve NX karotiyerler ile karot alınır. Bir sondaj programının düzenlenmesinde, deliklerin uygun eğim açılarında tüm kaya türleri ile kesişmesine dikkat edilmelidir. Örneğin, biyotit gnays bantları düzensiz dağılımda olabilir. Sondaj yanlış yapılmış ise mevcut olan bu tür yabancı maddelerin miktarı hakkında doğru sonuçlara varilamaz.

Sondaj deliklerinin aralığı, kayanın tek düzeliği ve araştırmanın evresine göre belirlenir. İlk sondaj geniş çaptadır, ardından muhtemelen $122 \mathrm{~m}$ (400 ft) aralıkla grid sondaj işlemi yapılır.

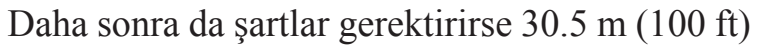
veya daha az aralık birakılarak devam edilir

Nefelinli siyenit için jeofizik ve jeokimyasal teknikler araştırmanın normal bir parçası değildir. Ancak sismik araştırmalar, örtü tabakasının derinliğinin belirlenmesine yardımcı olmak için faydalı olabilir.

\section{Diğer Hususlar}

Piyasanın büyüklüğü ve karakteri, nakliye şekli ve maliyeti, yardımcı hizmetlerin kullanılabilirliği, işgücü arzı ve kısıtlayıcı olabilecek kanunlar gibi hususlara dikkat edilmelidir. Bunlara araştırmanın erken safhasında gerekli önemin verilmesi, maden yataklarından hangisinin en büyük değere sahip olduğuna karar vermek için bir temel oluşturabilir (Kennedy, 1990).

\section{Madencilik}

Nefelinli siyenit genellikle standart açık işletme madenciliği ya da taş ocakçılığ1 yöntemiyle çıkartılmaktadır. $\mathrm{Bu}$ maden yataklarında delme ve patlatma uygulanmaktadır. Hammadde önden yükleyiciler ile kamyonetlere yüklenir. Diğer taraftan Norveç ve Rusya'daki madenlerde yeraltı madencilik yöntemleri kullanılmaktadır. Rusya'da 600-700 metre derinlikte blok göçertme yöntemi kullanılırken, Norveç'te yeraltı oda-topuk yöntemi ile madencilik yapılmaktadır (McLemore vd., 2006). Şekil 2'de Blue Mountain (Kanada) nefelinli siyenitler için uygulanan zenginleştirme yönteminin akış şeması görülmektedir.

\section{EKONOMIKK FAKTÖRLER}

\section{Talep ve Tüketim}

Doğu Avrupa ve Çin gibi ülkelerde yaşam düzeyinin artmasına bağlı olarak sağlık gereçleri, beyaz pişen ürünler, yer ve duvar karolar1, düz cam alanlarında beklendiği gibi nefelinli siyenit için talep artmaktadır. Diğer taraftan PET (polietilen tereftalat), alüminyum ve kağıt kapların kullanımının artması ve camların geri dönüşümünün artması sebebiyle cam kaplara talep azalmıştır (NSW, 2008).

Feldispat ve nefelinli siyenitin ana tüketicileri olan ülkeler, Avrupa'da İtalya, İspanya, Birleşik Krallık, Almanya ve Fransa; Asya Pasifik bölgesinde ise Çin ve Hindistan'dır.

Kanada ve Norveç'te çıkarılan nefelinli siyenitlerin yaklaşık olarak \%70'i cam üretimde tüketilmektedir. Bununla beraber Norveç nefelinli siyenitinin $\% 28$ 'i seramiklerde ve $\% 2$ 'si dolgu maddelerinde kullanılmaktadır. Kanada madenlerindeki üretimin yaklaşık olarak \%15'i seramikler ve dolgu maddesi uygulamaları için kullanılmaktadır (Ciullo, 1996). Rusya'daki üretimin büyük kısmı ile bölgesel bazda alüminyum üretilmektedir. 
Haner, Demir

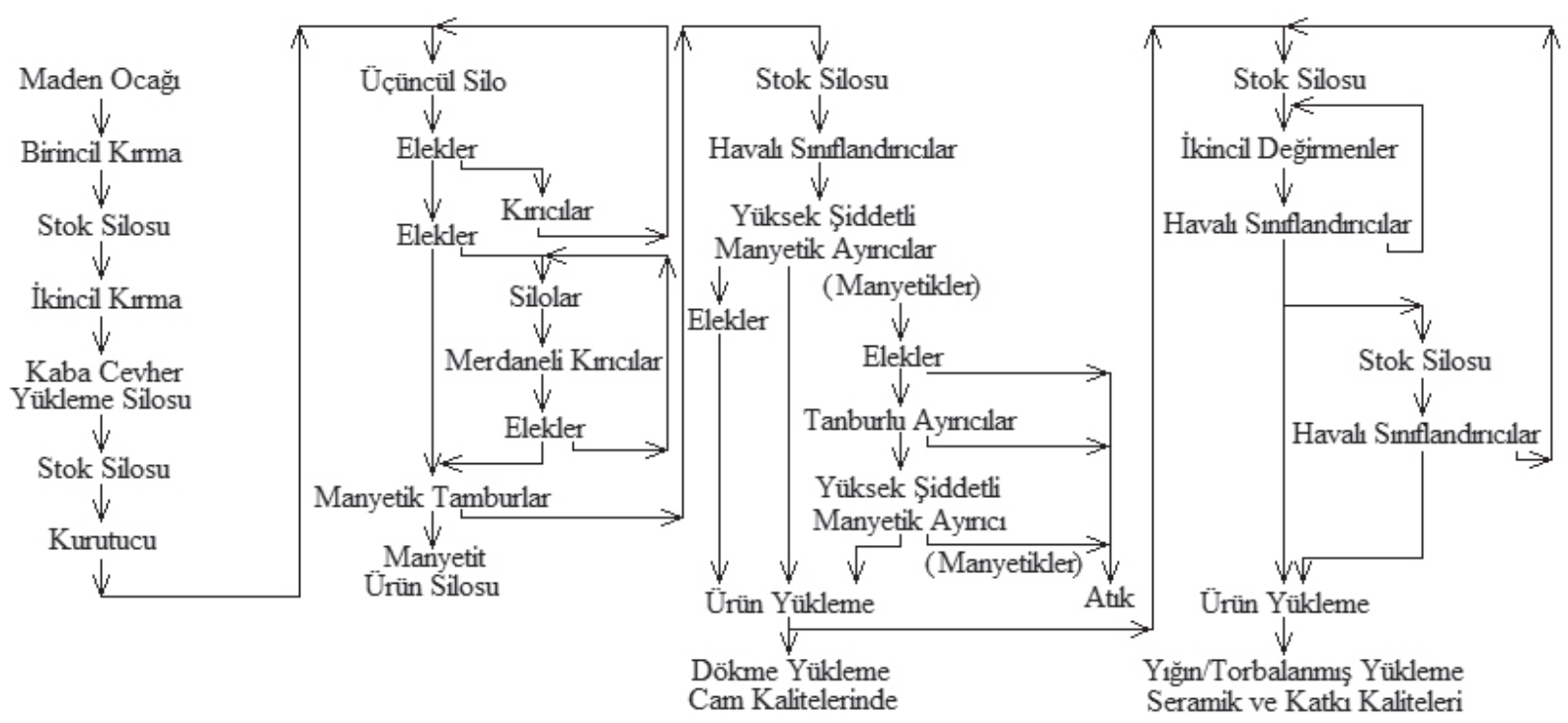

Şekil 2. Ontario Blue Mountain nefelinli siyenitinden mineral ürünler için üretim işlemi(Nephton tesisi) (Dolan vd., 1991).

Figure 2. Production process for mineral products from Blue Mountain nepheline syenite, Ontario (Nephton Plant) (Dolan et al., 1991).

Nefelinli siyenit, uluslararası tanımlamada, "Lösit; nefelin ve nefelinli siyenit (harmonized system code: 252930)" ad1 altında siniflandırılmaktadır. Bu nedenle sadece nefelinli siyenit için ihracat ve ithalat rakamları hakkında bilgi sahibi olmak mümkün olmamaktadır. Türkiye 2016 yılı verilerine göre "Lösit; nefelin ve siyenit nefelin"in yaklaşık olarak 33.824 tonunu ihraç ve 1766 tonunu da ithal etmiştir. İhracattan 3.378.232 TL kazanilırken, ithalata 2.028.955 TL ödemiştir (TÜİK, 2016).

\section{Fiyatlar}

Türkiye'de, yer kabuğunda ve su kaynaklarında doğal olarak bulunan, ekonomik ve ticari değeri olan petrol, doğal gaz, jeotermal ve su kaynakları dışında kalan her türlü madde, 5177 say1lı kanuna göre madendir. Enerji ve Tabi Kaynaklar Bakanlığı tarafindan Maden Kanununda IV-A grubunda ruhsatlandirilan nefelinli siyenit madeni için, 2016 yılı Ocak ay1 başı satış fiyatı KDV ve nakliye hariç $45 \mathrm{TL} /$ ton olarak belirlenmiştir (MİGEM, 2016).

Nefelinli siyenitin, 2008 y1lı Norveç cam kalitesinde (0.5 mm yı̆̆ın) FOL İngiltere limanda teslim fiyat $97 \mathrm{GBP} /$ ton, seramik kalitesinde (45 mikron yığın) FOL İngiltere limanda ise 146 GBP/ton'dur (Stary vd., 2009). 2013 yılı Norveç FOB fiyat1 750 NOK/ton'dur (Smelror, 2014).

\section{SONUÇLAR}

Nefelinli siyenitin malzemeye kazandırdığ 1 çok sayıdaki özellikler nedeniyle, dünya genelinde geniş bir kullanım alanına sahiptir. Düşük silis içeren, ucuz bir alümina ve alkali kaynağıdır. Diğer feldispat türlerine nazaran daha yüksek alümina/alkali oranına sahiptir. Alümina/alkali oranının yüksek olması ise çizilme dayanımı, mukavemet, 1sıl dayanım, 
kimyasal dayanımın yanı sıra düşük ergime sicaklığg anlamına da gelmektedir.

Nefelinli siyenitin bilinen kaynakları, yakın gelecek için öngörülen dünya talebini karşılamaya yetecek seviyededir. Ancak İtalya, İspanya, Brezilya, Çin ve Meksika gibi ülkelerdeki seramik üretimi artışına paralel olarak nefelinli siyenite olan talep artabilecektir. Nefelinli siyenitin ana tüketim alanlarından diğeri cam ürünleridir. Fakat atık cam ambalajların sonsuz bir şekilde geri dönüşümü olduğu için, bu alanlarda nefelinli siyenit talebi azalacağ1 düşünülmektedir.

Türkiye'nin Kurşehir ilinin Buzlukdağ 1 bölgesinde çok kaliteli nefelinli siyenit yatakları bulunmaktadır. Yıllık yaklaşık olarak 50000 ton üretimi yapılan nefelinli siyenitin, yurtiçindeki çeşitli sektörlerde tüketimi 20000 ton civarındadır. Uygulama alanı kısitlı olması rağmen, nefelinli siyenit ile ilgili yapılan araştırma çalışmaları kapsamında tüketim miktarının artması beklenmektedir.

\section{KAYNAKLAR}

Brown, T.J., Idoine, N.E., Raycraft, E.R., Shaw, R.A., Deady, E.A., Hobbs, S.F., Bide, T., 2017. World mineral production 2011-15. British Geological Survey, $87 \mathrm{p}$.

BS, 2015. B\&S Yatırım A.Ş., Türkiye. http://www.bsnefelin.com/tr/index.php, son erişim 12.02.2018.

Ciullo, P.A., 1996. Industrial minerals and their uses. Noyes Publications, New Jersey, No:96-29173, $632 \mathrm{p}$.

Deniz, K., 2010. Buzlukdağı (Kırşehir) alkali magmatik kayaçların jeolojisi, petrolojisi ve konfokal raman spektrometresi ile incelenmesi. Ankara Üniversitesi Fen Bilimleri Enstitüsü, Ankara, Yüksek Lisans Tezi, $138 \mathrm{~s}$.

Dolan, M.L., Hains, D.H., Ash, D.R., 1991. Highalumina rocks in Ontario: resources and process technology. Queen's Printer, Ontario, 130 p.
Guillet, G.R., 1994. Nepheline syenite. (editor: D.D. Carr). Industrial Minerals and Rocks $\left(6^{\text {th }}\right.$ Edition). Society for Mining, Metallurgy, and Exploration, Inc., Littleton, Colorado, 711-730.

Kennedy, B.A., 1990. Nepheline syenite. (editor: B.A. Kennedy). Surface Mining ( $2^{\text {nd }}$ Edition) Society for Mining, Metallurgy and Exploration, Inc., Littleton, Colorado, 214-217.

Kunduracı, N., Aydın, T., Akbay, A., 2016. The effect of nepheline syenite addition on the sintering behaviour of sanitaryware bodies. Journal of the Australian Ceramic Society, 52 (2), 82-86.

McLemore, V.T., 2006. Nepheline Syenite. (editor: J.E. Kogel, N.C. Trivedi, J.M. Barker, S.T. Krukowski). Industrial Minerals \& Rocks $\left(7^{\text {th }}\right.$ Edition). Published by Society for Mining, Metallurgy, and Exploration, Inc., Colorado, 653-670.

McVey, H., 1988. A study of markets for British Columbia's nepheline syenite and feldspathic minerals. Mineral Marketing, Inc., No:0005032857, $50 \mathrm{p}$.

MİGEM, 2016. 4-A grubu madenler ocakbaşı satıș fiyatları. Maden İșleri Genel Müdürlüğü, http:// test.migem.gov.tr/duyurular/malikonular.html, son erişim 12.02.2018.

Smelror, M., 2014. Mineral resources in Norway 2013 production data and annual report. Geological Survey of Norway, No:2, $54 \mathrm{p}$.

MSDS, 2015. Nepheline syenite safety data sheet. Unimin Corporation, No: 013-U-GHS https:// www.psh.ca/MSDS/Nepheline\%20Syenite.pdf, son erişim 12.02.2018.

MTA, 2016. Feldispat (feldspat). Maden Tetkik ve Arama Genel Müdürlüğü, http://www.mta. gov.tr/v3.0/bilgi-merkezi/feldispat, son erişim: 12.02.2018.

Negm, A.T., Abouzeid, A.Z., Boulos, T., Ahmed, H., 2000. Nepheline syenite processing for glass and ceramic industries. Physicochemical Problems of Mineral Processing, 34, 5-16.

NSW, 2008. Nepheline syenite. Government of New South Wales Department of Primary Industries. https://www.resourcesandenergy.nsw.gov.au/ data/assets/pdf_file/0010/238177/Nepheline. pdf, son erişim: 12.02 .2018 . 
O'Connor, D.E., 2011. Petrogenesis of nepheline syenites and phonolites from the lofdal intrusive complex, Kunene region, Namibia. Dalhousie University, Department of Earth Sciences, Halifax, Nova Scotia, Bachelor of Science Degree, $103 \mathrm{p}$.

O’Driscoll, M., 2005. Fineton finds its niche: Industrial Minerals, No:456, September, 68-69.

Platt, R.G., 1996. Nepheline-syenite complexes-an overviev. (editor: R.H. Mitchell). Undersaturated Alkaline Rocks: Mineralogy, Petrogenesis, and Economic Potential. Mineralogical Association of Canada, Ottawa, 63-100.

Salem, A., Jazayerib, S.H., Rastellic, E., Timellinic, G., 2009. Effect of nepheline syenite on the colorant behavior of porcelain stoneware body. Journal of Ceramic Processing Research, 10 (5), 621-627.

Sarıiz, K., Nuhoğlu, İ., 1992. Endüstriyel hammadde yatakları ve madenciliği. Anadolu Üniversitesi Mühendislik-Mimarlık Fakültesi Yayınları, Eskişehir, Say1: 62, 443 s.

Stary, J., Kavina, P., Vanecek, M., Sitensky, I., Kotkova, J., Hodkova, T., 2009. Mineral commodity summaries of the Czech Repuclic. Ministry of the Environment Czech Geological Survey-Geofond, $492 \mathrm{p}$.

Tait, K.T., Sokolava, E., Hawthorne, F.C., 2003. The ctystal chemistry of nepheline. The Canadian Mineralogist, 41, 61-70.

Tanner, A.O., 2010. Feldspar and nepheline syenite. Minerals Yearbook, Metals and Minerals 2010, Mines Bureau, Geological Survey and Interior Department, V. 1, 1114 p.
Tanner, A.O., 2012. Feldspar and nepheline syenite. 2010 Minerals yearbook, U.S. Geological Survey, https://minerals.usgs.gov/minerals/pubs/ commodity/feldspar/myb1-2010-felds.pdf, son erişim: 12.02.2018.

Tanner, A.O., 2015. Feldspar and nepheline syenite. 2013 Minerals yearbook, U.S. Geological Survey, https://minerals.usgs.gov/minerals/pubs/ commodity/feldspar/myb1-2013-felds.pdf, son erişim: 12.02.2018.

Tanner, A.O., 2016. Feldspar and nepheline syenite. 2014 Minerals yearbook, U.S. Geological Survey, https://minerals.usgs.gov/minerals/pubs/ commodity/feldspar/myb1-2014-felds.pdf, son erişim: 12.02.2018

Tanner, A.O., 2017. Feldspar and nepheline syenite. Mineral commodity summaries, U.S. Geological Survey, https://minerals.usgs.gov/minerals/pubs/ commodity/feldspar/mcs-2017-felds.pdf, son erişim: 12.02 .2018 .

Tuzcu, N., 1992. Petrografi-I (Magmatik Kayaçlar) (3. Bask1). Dokuz Eylül Üniversitesi MühendislikMimarlık Fakültesi Basım Ünitesi, İzmir, Sayı: $100,222 \mathrm{~s}$.

TÜİK, 2016. D1ş ticaret istatistikleri. Türkiye İstatistik Kurumu, https://biruni.tuik.gov.tr/disticaretapp/ menu.zul, son erişim: 12.02.2018.

Unimin, 2014. A History in Havelock. Canadian Nepheline Modernization, http:// canadiannepheline.ca/\#our-history, son erişim: 12.02.2018.

Woolley, A.R., 1987. Alkaline rocks and carbonatites of the World-Part 1: North and South America. The University of Texas Press, Austin, Texas, $216 \mathrm{p}$. 